\title{
Directions Developing Quality Management Systems of Mechanical Engineering Enterprises
}

\author{
Vavilin Yaroslav* \\ Department of "Quality Management, Standardization and Metrology" Bryansk State Technical University, Bryansk, Russia
}

*Corresponding author: Vavilin Yaroslav, Bryansk State Technical University, department of "Quality Management, Standardization and Metrology" (7, 50th anniversary of October, Bryansk, 241035), Candidate of Technical Sciences, Associate Professor of the Department "Quality Management, Standardization and Metrology", Russia.
Received Date: November 19, 2020

Published Date: November 25, 2020

\section{Abstract}

The article deals with the development of the quality management system in the context of changing economic policy and increasing competition. The article considers the main directions of developing integrated management systems in organizations.

Keywords: Quality system; Mechanical engineering; Integration

\section{Introduction}

In conditions of high competition and limited resources (especially financial), the issue of strategy for organizing machinebuilding production to reduce all types of costs and to increase its efficiency, as well as search for competitive advantages becomes relevant [1-5].

\section{Discussion}

Modern realities of the struggle for the consumer and reduction of all types of costs lead organizations to realize the need not only to create ISM, but also to expand them by introducing various subsystems.

The integrated quality management system is defined as a part of the general management system that meets the requirements of two or more standards and which functions as a whole. The introduction of such systems allows us to solve a number of tasks to optimize document flow, in particular [2-5]:

- $\quad$ appearing repetitive processes;
- complexity of perceiving interrelations and system element subordination;

- high labor input and resource requirements for independent implementation.

Another area of product quality assurance is the introduction of a modern quality philosophy. Among the most popular in recent years, we can distinguish lean production methods (mapping the flow of value creation; pulling line production; kanban; kaizen; 5S system; SMED system; TPM system; Just-In-Time system; visualization). However, the simultaneous implementation of all these elements may not lead to the desired result ("process paradox" - a large amount of resources spent does not lead to a significant effect).

In this regard, the issue of optimal choice of priority tools and methods for managing the quality of products becomes relevant. The two criteria with a ten-point rating scale are proposed to use: the importance of the element (1 - low, 10 - high) and the 
payback period (1 - slow, 10 - fast). The final score is obtained by multiplying and is described as follows: 1-16-negligibly level of recommendation for the implementation; 17-32-low;

Ranking of lean production elements.

\begin{tabular}{|c|c|c|c|}
\hline Name of the tool & The absence of QMS & The presence of QMS & At having an integrated quality management system \\
\hline Mapping the value stream & 56 & 72 & 81 \\
\hline Pulling line production & 25 & 64 & 49 \\
\hline Kanban & 25 & 30 & 49 \\
\hline Kaizen & 25 & 42 & 90 \\
\hline System 5S & 64 & 72 & 64 \\
\hline SMED system & 35 & 56 & 72 \\
\hline The TPM system & 48 & 64 & 49 \\
\hline Just-In-Time System & 16 & 45 & 100 \\
\hline Visualization & 72 & 81 & \\
\hline
\end{tabular}

\section{Conclusion}

Applying this kind of ranking assessment will allow a rational approach to the question of the sequence of implementation of quality management elements and achieve a significant reduction in the payback period for implementation.

\section{Acknowledgement}

None.

\section{Conflict of Interest}

No conflict of interest.

\section{References}

1. Popova OG, Smolentsev VM (2016) Quality management in competitive conditions. Economics of agriculture in Russia 12: 18. 33-48-medium; 49 - 64 - high; 65 - 100 - primary. The evaluation results of lean production elements are shown in the table.
2. Semin SV (2019) Introduction of an integrated management system as a tool that ensures the successful operation of the organization. Collection of scientific works of international scientific conference of theoretical and applied development. Moscow: Publishing house: Infiniti (Ufa), Pp. 130-137.

3. Lapidus VA, Kastorskaya LV, Serov ME, Voinova EG (2018) Principles and approaches of management in the quality assurance system. Methods of quality management $7: 36-42$.

4. Golubeva OA, Vasiliev AS (2018) Relevance of development of integrated quality management systems. Materials of international scientificpractical Conf. "Science today: reality and prospects". Publishing house: “Marker", pp. 35-36.

5. Barkalov SA, Morozov VP, Moiseev SI (2018) System of principles of integrated management. collection of articles on the materials of the VII international scientific-practical conf. "Problems of modern economic, legal and natural sciences in Russia-synthesis of sciences in a competitive economy". Voronezh state technical University, pp. 76-78. 